\title{
Satisfaction with the political domain of local government in a contemporary British city
}

\section{David C. Broadstock ${ }^{1}$ and Alan Collins ${ }^{2}$}

1. Research Institute of Economics and Management, Southwestern University of Finance and Economics, Chengdu, China.

2. University of Portsmouth, UK and Rhodes University, Grahamstown, South Africa

Contact:

David Broadstock

Research Institute of Economics and Management

Southwest University of Finance and Economics

55 Gunanghua Cun Jie

Chengdu, Sichuan, 610074, China

Email: davidbroadstock@swufe.edu.cn

Tel: 008615208340910 


\title{
Satisfaction with the Political Domain of local Government in a Contemporary British City
}

\begin{abstract}
This paper explores satisfaction with the political domain of local government performance, using survey data from a contemporary British city as the empirical context. It employs a factoraugmented ordered logit analysis of data emerging from a representative city-wide series of over one thousand household interviews. Affective reactions to local economic performance and policy effectiveness are constructed in the spirit of the approach used in earlier work by social scientists. The key significant influences that raise or depress satisfaction at this geographical level are presented. Affective reactions to past policy and the economy are both shown to be statistically significant, but with reactions to the economy being negative while those for other policy reactions seemingly positive.
\end{abstract}

Key words: Satisfaction with the political domain, local government, factor-augmented ordered logit. 


\section{Introduction}

This paper seeks to extend to a city level some of the higher level life satisfaction studies that focus on central government performance. Whiteley et al. (2010) provide a detailed and extensive review of the range of studies that investigate the determinants of life satisfaction and particularly the role of the state (specifically central government) in various dimensions that impinge on individual subjective well-being (SWB). This is an increasingly widespread and significant area of political concern. In democracies the extent to which an individual citizen feels represented and their affinity with a political minority or majority may impact on their satisfaction with democratic political institutions and systems (Anderson and Guillory 1997). Further, popular expressions of political disaffection and discontent in the media and serial declines in voter turnout in some elections have directed considerable attention to social capital and institutional explanations for voter apathy, protest and perceptions of a democratic deficit (see, for example the body of work presented in Torcal and Montero (2006). This study provides an inquiry into the SWB of households with respect to the specific domain of local government performance.

The societal and scientific relevance of this work arises from the resolution of the study namely by focusing at the household level with a special emphasis placed on how various dimensions of the local political domain can alter life-satisfaction outcomes. Local governments often have a certain degree of flexibility to implement the national policy agenda, as well as various discretionary spending patterns and in some cases the implementation of by-laws and legal instruments that all create a (admittedly modest) degree of separation between local and national government. Intuitively speaking the public have a greater affinity with local government than national government. It is posited that it would be reasonable to expect that at a city level, people experience the 'cutting edge' of government performance in terms of policy outcomes impacting on their immediate surroundings and in relation to public services that impinge on their daily lives. One might even expect clearer results than what would be observed with respect to the central government or regional level. We know the role of local government differs from that of a national 
or state government. Broadly speaking, local government in the UK has limited fiscal control, with the majority of their budgets being allocated to them by the central government. The local authority generally retains local budget allocation power, but in allocating the budget is often bound by legislated service delivery requirements e.g. access to healthcare/education, provision of police/fire/ambulance services etc.

The local government jurisdiction under scrutiny in this study is the City of Portsmouth in the United Kingdom (see Figure 1) which has statutory responsibilities for much school education, public housing, street repair, cleansing, planning, licensing various business establishments, maintaining many social care responsibilities as well as engaging in a large raft of other non-statutory responsibilities pertaining to, for example, the provision of various cultural and leisure facilities. The coverage of its activities is evident from Portsmouth City Council (2012). Portsmouth is not a wholly typical city in that it has a lower non-white residential population than most UK cities, is physically very compact leading to a very high population density, and is the UK's only island city. While these create a city atmosphere with some unique features, Portsmouth is in many other ways a good reflection of many modern English cities. ${ }^{i}$

Figure 1: Location of the city of Portsmouth, Hampshire, England 


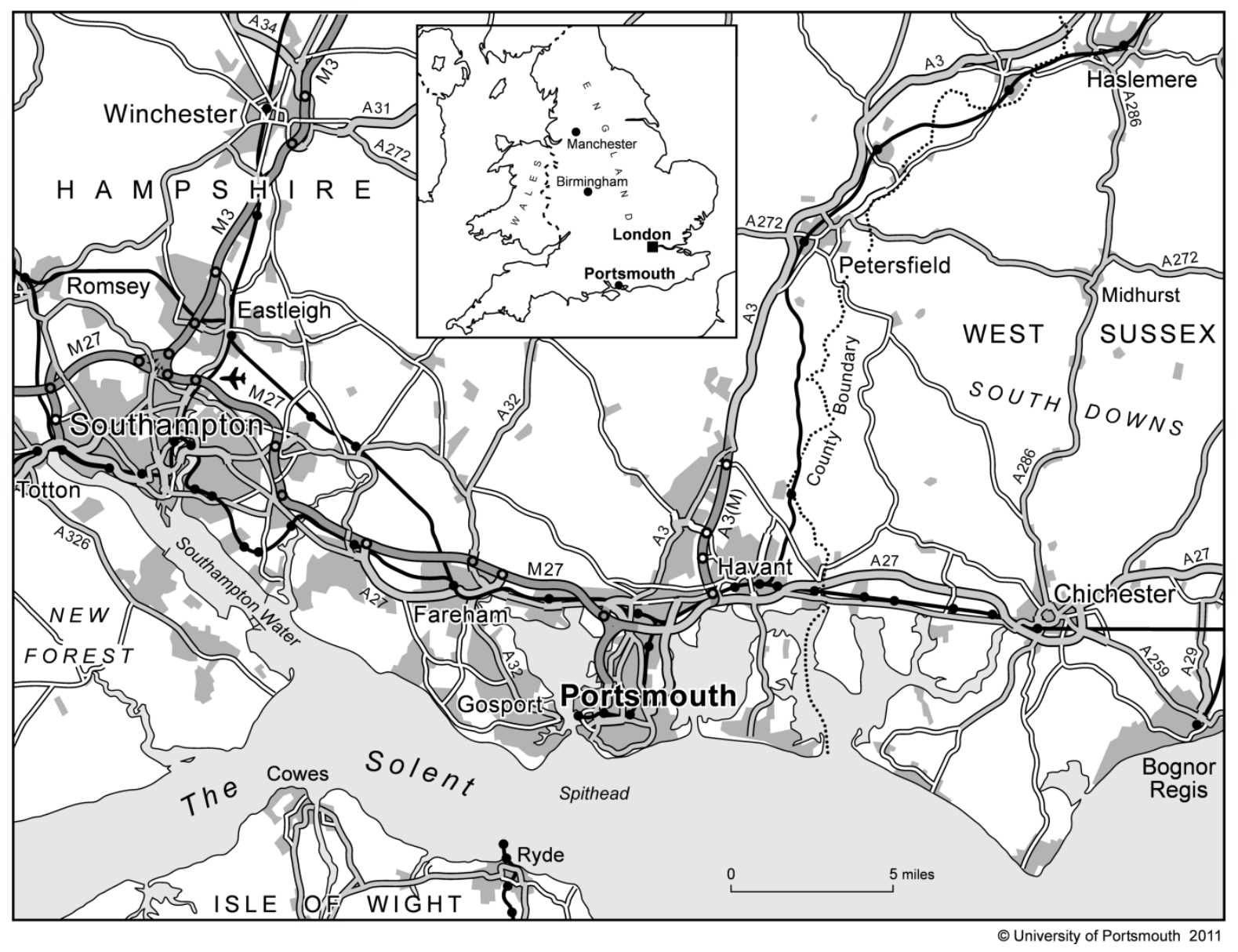

In addition to exploring the subjective dimensions of well-being and life satisfaction, some studies have further explored aspects of life satisfaction that may be influenced/determined by 'objective' dimensions. For example Okulicz-Kozaryn (2013) examined various objective indicators stemming from the concept of 'liveability' which include hard and soft infrastructures, such as transport infrastructure networks, the availability of green space and perhaps even some less visible features such as the acceptability of public-smoking and binge-drinking (Okulicz-Kozaryn, 2014). These objective factors can establish universal boundaries of life satisfaction common to many of the residents within an area. It is not feasible to explore these here given the nature of the data used in this study (discussed in more detail below), but this will not impinge on the value and accuracy of the story relating to local government performance, since the objective measures will in effect be absorbed (within the constant terms) in the empirical specification, allowing for carefully isolated 
reactions to local government indicators to be obtained. Conversely, focusing on subjective measures provides the added advantage of describing more directly the (satisfaction) outcomes of community engagement as opposed to the sentiment of residents with regard to the structures and norms reflected by some of the objective measures described above.

This study is organized in the following manner: the next section outlines the data and empirical methodology; the results and discussion are then presented. Some concluding remarks are offered in the final section.

\section{Data and Method of Analysis}

The data used in this study is obtained from a resident's survey carried out by Portsmouth City Council in 2007. Portsmouth is the second largest city in the County of Hampshire lying on the south coast of England. The labour market is dominated by a small number of large employers, of which the City Council, the University of Portsmouth and IBM dominate. It has an urban population of approximately 200,000 people. The survey was rigorously conducted by a professional market research organization - Ipsos Mori and commissioned by Portsmouth City Council. The survey sampled covered 1094 households. Approximately 92\% of the households contacted responded to this survey leaving a sample size of 1005. Respondents were interviewed face-to-face in their own homes between 6 October and 14 December 2007. Respondents were randomly selected from sampling points across the city, using a stratified sampling method based on the 2001 census (gender, age and work status). Only households within the Portsmouth boundary where the respondent was aged 16 or over were included. The survey includes a total of fifty four questions.

There have been critical and nuanced assessments of the scope and ambit of measures of subjective well-being as well as the nature of statistical estimation relating to happiness and life satisfaction equations. Generally the individual scores have been interpreted in cardinal terms by psychologists/sociologists, who have run OLS regressions on happiness and changes in happiness. 
This has caused some methodological concern, particularly amongst economists, who have an inherent distrust of assumptions of ordinal and inter-personal comparability in utility. Is person A's difference between happiness level 7 and 9 the same as their difference between level 5 and 7 or person B's 5 and 7 or 7 and 9 ? Economists have usually assumed only ordinality and have mainly used ordered latent response models. The work of Ferrer-i-Carbonell and Frijters (2004) suggests, however, that assuming cardinality or ordinality of happiness scores makes little difference.

In specifying the empirical model of satisfaction with local government performance for individual $i$, Satisfaction $_{i}$, an ordered logit model of satisfaction with the political domain of local government (henceforth SPDLG) incorporating a number of features contained in related studies is established:

Satisfaction $_{i}=f\left(\right.$ age, age $^{2}$, female $^{*}$ age, female $*$ age $e^{2}$,disability _self, disability _other, education, ethnicity, gender, house_own, income,children,car, flood_concern, climate_concern,social_grade,retired,unemployed,volunteer, political_efficacy, community_efficacy, policy_exp erience, affective_economy, affective _ policy)

Where Satisfaction ${ }_{i}$ is an ordinal measure of the level of satisfaction based on the following survey question: "Overall, how satisfied or dissatisfied are you with the way Portsmouth City Council is running the city?", with answers ranging between 1 for very dissatisfied and 5 for very satisfied. This specification is rich, making use of a large part of the available survey data. Age effects enter into the model in a non-linear fashion allowing for a general U-shape effect to be estimated as found in previous studies. Gender effects are admitted by including an intercept shift (gender) as well as interactive terms with age (female*age and female*age ${ }^{2}$ ). According to Dolan et al. (2008) for age there is also a U-shaped relationship in subjective well-being with a bottoming out in the 32-50 band whilst for Gender - there is mixed evidence of a positive effect for women as compared to men. The effects of a physical disability (either self, the person answering the survey on behalf of the household, or other, another member in the household) are controlled for. A range of standard socio-economic indicators are also included, namely education, non-white, home/vehicle ownership, 
income level, social status and an indicator for if the household has children. Luechinger and Raschky (2009) specify the income response in terms of a Constant Relative Risk Aversion function (CRRA). This is interesting, but given the discrete and broad categories of income used in the study survey, this did not seem appropriate to attempt here.i

In addition to the standard socioeconomic control variables, the model features a number of local government performance measures. The variables are defined in Table 1 with descriptive statistics presented in Table 2. In brief, Portsmouth residents display a happy disposition with both the mean and median satisfaction score being 4 (= 'satisfied'). Notwithstanding their generally positive nature, it can be seen that most residents harbour less optimism regarding aspects of satisfaction with the domains of local government performance: it can for example be seen that around $20 \%$ of households have concern over the ability of the city to handle localized flooding, while a larger $32 \%$ of households are concerned over the city's ability to adapt to climate change. Some $44 \%$ of households feel they have a voice with local government, but only $24 \%$ feel they have a voice within the local community. The majority of these measures were constructed prior to estimation of the SPDLG model. Prior to outlining some estimation issues to control for non-reporting of certain socioeconomic indicators, the construction of the specific local government performance indicators are outlined in more detail.

Given the various indicators/dummy variables, the reference group is thus defined as households with income less than $f 2,500$, no car, no children, a household head who is a 'State pensioner, casual or lowest grade worker or unemployed with state benefits only', and where the survey respondent is a (white British) male.

Table 1: Description of estimation variables included in the empirical SPDLG model

\begin{tabular}{ll}
\hline \hline \multicolumn{1}{c}{ Variable } & Description \\
\hline Socioeconomic indicators & The age of the survey respondent \\
Age squared & The square of the age of the survey respondent \\
Female*age & The age of the survey respondent, conditional on the respondent being female \\
Female*age squared & The square of the age of the survey respondent, conditional on the respondent being \\
& female \\
Female & A dummy variable indicating if the respondent is female $(=1)$
\end{tabular}


Disabled (self)

Disabled (other)

Non-white

Home ownership

Vehicle ownership (single)

Vehicle ownership (multiple)

Children

Education

Income $£ 3,749$

Income $£ 4,999$

Income $f 7,499$

Income $£ 9,999$

Income $£ 12,499$

Income $₫ 15,599$

Income $\mathrm{f20,799}$

Income $f 25,999$

Income $₫ 31,199$

Income $\mathrm{f31,200+}$

Social grade $D$

Social grade $\mathrm{C} 2$

Social grade $\mathrm{C} 1$

Retired

Unemployed

volunteer

\section{Indicators of}

Flood concern

Climate concern

Political efficacy

Community efficacy

Policy experience

Affective policy

Notes:

(i) To help identify genuine and manageable climate change/flood concerns, these variables are only set equal to

A dummy variable indicating if the respondent is disabled $(=1)$

A dummy variable indicating whether there is a disabled resident other than the respondent in the household $(=1)$

A dummy variable indicating if the respondent is non-white $(=1)$

A dummy variable indicating if the household is owned by its residents $(=1)$

A dummy variable indicating if the household owns a vehicle $(=1)$

A dummy variable indicating if the household owns more than 1 vehicle $(=1)$

A dummy variable indicating if there are children in the household $(=1)$

An ordinal measure of educational attainment. Ranging from no formal education $(=1)$ through to university degree $(=4)$.

A dummy variable indicating if the household income lies between $£ 2,500-£ 3,749$ (=1)

A dummy variable indicating if the household income lies between $£ 3,800-f 4,999(=1)$

A dummy variable indicating if the household income lies between $f 5,000-f 7,999(=1)$

A dummy variable indicating if the household income lies between $£ 8,000-f 9,999(=1)$

A dummy variable indicating if the household income lies between $£ 10,000-£ 12,499(=1)$

A dummy variable indicating if the household income lies between $£ 12,500-£ 15,999(=1)$

A dummy variable indicating if the household income lies between $£ 16,000-£ 20,799(=1)$

A dummy variable indicating if the household income lies between $£ 20,800-£ 25,999(=1)$

A dummy variable indicating if the household income lies between $f 25,600-£ 31,199(=1)$

A dummy variable indicating if the household income is $f 31,200$ or greater $(=1)$

A dummy variable denoting if the chief income earner is a 'Semi and unskilled manual

workers' (=1)

A dummy variable denoting if the chief income earner is a 'Skilled manual workers' $(=1)$

A dummy variable denoting if the chief income earner is a 'Supervisory, clerical and junior managerial administrative or professional' $(=1)$

A dummy variable indicating if the respondent is retired $(=1)$

A dummy variable indicating if the respondent is unemployed $(=1)$

A dummy variable indicating if the does any volunteer work in the local community (=1)

\section{of local government}

A dummy variable indicating concern over the possibility of local flooding $(=1)$

A dummy variable indicating concern about the effects of climate change $(=1)$

A dummy variable describing if the household feels it has a voice with the local government (=1)

A dummy variable describing if the household feels it has a voice with the local community $(=1)$

A dummy variable indicating if the household is directly affecting by some policy that does not apply to all citizens $(=1$ ) including experience with policies covering: "Child and family health services (e.g. antenatal support, breast feeding, post natal depression)", "Childcare, pre-school and nursery education for children under 5", "Parenting support and advice", "Adult education", "Information on employment and services for families", "Drop-ins, parent \& toddler groups, family activities".

A measure of the affective reaction to local economic performance.

A measure of the affective reaction to local policy performance

\footnotetext{
one when the household feels that the local government can influence outcomes regarding climate change/flooding.
}

\title{
Measuring affective reactions to local policy and economic performance using factor analysis
}

\author{
Affective reactions to local economic performance and policy effectiveness are constructed in the
}

spirit of the approach used by Whiteley et al. (2010).iii The term affective relates to an experiential

perspective of policy and economic outcomes and these measures are therefore retrospective by

definition. The survey of Portsmouth residents included a number of questions asking respondents 
to gauge the success of the council with respect to key policy areas and general economic performance. These questions, the specific details of which are outlined in the appendix, are used together within a principal component analysis, the details of which are also included in the appendix, to construct two unique measures of affective reactions.

\section{Estimation of the SPDLG model in the presence of non-reporting}

Given some missing data for household income (approximately $30 \%$ of observations in total), estimation is conducted using a modified Monte-Carlo random sub-sampling (RS) design. ${ }^{\text {iv }}$ Random sub-sampling of a large dataset can help ensure that missing observations are themselves random within the subsample and hence can be defined as missing completely at random (MCAR). Furthermore, when missing data are of the type MCAR complete case analysis will produce theoretically unbiased parameter estimates. The re-sampling algorithm can be specified as:

1. Given a sample of $\mathrm{N}$ observations, draw a new sub-sample of $\mathrm{M}<\mathrm{N}$ observations randomly without replacement from the original sample;

2. From the sub-sample remove incomplete observations, if any, to produce a complete case sub-sample of $M^{*} \leq M$ observations;

a. It is worth acknowledging that $M^{*}$ for each replication may contain a different number of observations. While the overall sample sizes are modest, they are sufficiently large to consider that each replication is asymptotically unbiased. To help ensure this if $M^{*}$ contains less than 250 complete cases, the sample is disregarded and a new draw of $M$ is made.

3. Using the random sub-sample of the original dataset (containing the $M^{*} \leq M<N$ observations), estimate the desired model. In this paper this takes the form of an ordered logistic regression; 
4. Repeat steps 1-3 a large number of times $R$, recording the estimated parameters from each replication. This produces $R$ different parameter estimates, the mean of which should tend in probability to the true parameter.

Table 2: Descriptive statistics.

\begin{tabular}{|c|c|c|c|c|c|}
\hline Variable & Mean & Median & $\begin{array}{l}\text { Standard } \\
\text { deviation }\end{array}$ & Minimum & Maximum \\
\hline \multicolumn{6}{|l|}{ Socioeconomic indicators } \\
\hline Life satisfaction & 3.978 & 4 & 0.837 & 1 & 5 \\
\hline Age & 45.473 & 42 & 18.402 & 16 & 93 \\
\hline Female & 0.530 & 1 & 0.500 & 0 & 1 \\
\hline Disabled (self) & 0.155 & 0 & 0.362 & 0 & 1 \\
\hline Disabled (other) & 0.919 & 1 & 0.273 & 0 & 1 \\
\hline Non-white & 0.058 & 0 & 0.234 & 0 & 1 \\
\hline Home ownership & 0.255 & 0 & 0.436 & 0 & 1 \\
\hline Vehicle ownership (single) & 0.419 & 0 & 0.494 & 0 & 1 \\
\hline Vehicle ownership (multiple) & 0.245 & 0 & 0.431 & 0 & 1 \\
\hline Children & 0.270 & 0 & 0.444 & 0 & 1 \\
\hline Education & 1.938 & 1 & 1.107 & 1 & 4 \\
\hline Income $£ 4,999$ & 0.056 & 0 & 0.231 & 0 & 1 \\
\hline Income $f 7,499$ & 0.105 & 0 & 0.306 & 0 & 1 \\
\hline Income $£ 9,999$ & 0.100 & 0 & 0.300 & 0 & 1 \\
\hline Income $f 12,499$ & 0.091 & 0 & 0.287 & 0 & 1 \\
\hline Income $f 15,599$ & 0.083 & 0 & 0.276 & 0 & 1 \\
\hline Income $£ 20,799$ & 0.072 & 0 & 0.258 & 0 & 1 \\
\hline Income $f 25,999$ & 0.075 & 0 & 0.264 & 0 & 1 \\
\hline Income $f 31,199$ & 0.092 & 0 & 0.290 & 0 & 1 \\
\hline Income $£ 31,200+$ & 0.272 & 0 & 0.445 & 0 & 1 \\
\hline Social grade D & 0.170 & 0 & 0.376 & 0 & 1 \\
\hline Social grade C2 & 0.184 & 0 & 0.388 & 0 & 1 \\
\hline Social grade C1 & 0.333 & 0 & 0.472 & 0 & 1 \\
\hline Retired & 0.228 & 0 & 0.420 & 0 & 1 \\
\hline Unemployed & 0.050 & 0 & 0.218 & 0 & 1 \\
\hline volunteer & 0.106 & 0 & 0.308 & 0 & 1 \\
\hline \multicolumn{6}{|c|}{ Indicators of satisfaction with domains of local government } \\
\hline Flood concern & 0.198 & 0 & 0.399 & 0 & 1 \\
\hline Climate concern & 0.320 & 0 & 0.467 & 0 & 1 \\
\hline Political efficacy & 0.439 & 0 & 0.497 & 0 & 1 \\
\hline Community efficacy & 0.242 & 0 & 0.429 & 0 & 1 \\
\hline Policy experience & 0.139 & 0 & 0.346 & 0 & 1 \\
\hline Affective economy & -0.024 & 0.099 & 0.779 & -2.470 & 1.724 \\
\hline Affective policy & -0.035 & -0.009 & 0.928 & -3.428 & 2.706 \\
\hline Observations & 640 & & & & \\
\hline
\end{tabular}

In application, for each replication a sub-sample of $M=600$ observations is drawn, and 10,000

replications are done in total. Models parameters are subsequently evaluated using the empirical coefficient distributions from the 10,000 replications, where a kernel density approximation is used 
to obtain the most likely (or maximum density) coefficient value, hence correcting for possible bias/asymmetry in the coefficient distributions. ${ }^{\vee}$

In the table in Appendix B an alternative set of descriptive statistics is offered, parts of which are summarized here, that is based on a simple fourfold typology looking into the characteristics of households that are: satisfied and with an uncritical perspective of local policy (measured in terms of having an 'affective policy' score in the upper $15 \%$ of households); satisfied and with a critical perspective of local policy (measured in terms of having an 'affective policy' score in the lower $15 \%$ of households); unsatisfied and with an uncritical perspective of local policy (measured in terms of having an 'affective policy' score in the upper $15 \%$ of households) and; unsatisfied and with a critical perspective of local policy (measured in terms of having an 'affective policy' score in the lower $15 \%$ of households). Unsatisfied -critical households are arguably the most important of these groups, being the most immediate concern for local government in terms of needing to improve their satisfaction with the political domain of local government (and avoid losing votes). This fourfold typology allows for some appreciation of the household characteristics more synonymous with each type.

Taking first the differences between the satisfied and unsatisfied households, variables which more clearly have different means across the groups include: age, younger households are generally more satisfied; households that own cars tend to be less satisfied; those households who have direct policy experience are more satisfied; households with low scores for political efficacy are less satisfied. Regarding the differences between critical and uncritical households: households that are uncritical also to be more concerned about either local flooding or climate change; those with community efficacy are more likely to be uncritical; retired households are more likely to be critical of local policy, as are disabled households and also higher educated households; non-white households and households with cars are also more likely to be uncritical. Some variables which do not have such an obvious role, at least in this simple four-way typology, include income (though 
higher social grades such as managerial staff are more likely to be uncritical), employment status, gender and being a community volunteer.

In trying to discern more concretely the type of household that is of the unsatisfied-critical disposition, these are generally households that are elderly, retired and with disability. These are however also households with a generally lower level of experience with local policy and quite low level of political efficacy. The implication of this is that in trying to remedy the concerns of the unsatisfied-critical type of households, the local government may seek to place a greater effort on educating pensioners and those with disability of benefits/policy schemes available to them, and also the alternative ways which they can express their views to local government. This descriptive analysis should, however, be reinforced by the results of the SPDLG model presented in the next section.

\section{Empirical Results}

The household level estimation results are presented in Table 3. The discussion is separated into two main parts. Firstly the socioeconomic/demographic characteristics are discussed, this is important to establish that the core components of the SPDLG model are broadly consistent with previous literature. Following this the government performance measures are discussed in more detail. The government performance indicators include concerns regarding flooding and climate change. In one sense these are control variables to distinguish service satisfaction to the household. At the same time they offer a view of the household's beliefs in the local government to mitigate the impacts of local and global 'threats' upon households in the city. 
Table 3: Household-level Ordered Logit SPDLG Model for Portsmouth City

\begin{tabular}{|c|c|c|c|c|}
\hline Variable & Estimate & & Standard error & Absolute t-statistic \\
\hline \multicolumn{5}{|l|}{ Socioeconomic indicators } \\
\hline Age & -0.0507 & $* * *$ & 0.0059 & 8.5920 \\
\hline Age squared & 0.0005 & $* * *$ & 0.0001 & 8.4855 \\
\hline Female*age & 0.0110 & & 0.0085 & 1.2977 \\
\hline Female*age squared & 0.0000 & & 0.0001 & 0.4332 \\
\hline Female & -0.3068 & $*$ & 0.1854 & 1.6546 \\
\hline Disabled (self) & 0.2196 & $* * *$ & 0.0439 & 5.0050 \\
\hline Disabled (other) & -0.0682 & & 0.0533 & 1.2790 \\
\hline Non-white & 0.5854 & $* * *$ & 0.0676 & 8.6623 \\
\hline Home ownership & 0.0032 & & 0.0430 & 0.0752 \\
\hline Vehicle ownership (single) & -0.0427 & & 0.0345 & 1.2370 \\
\hline Vehicle ownership (multiple) & 0.1166 & $* *$ & 0.0465 & 2.5078 \\
\hline Children & -0.1085 & $* * *$ & 0.0290 & 3.7400 \\
\hline Education & -0.0073 & & 0.0208 & 0.3519 \\
\hline Income $£ 4,999$ & 0.3914 & $* * *$ & 0.0750 & 5.2165 \\
\hline Income $f 7,499$ & 0.0341 & & 0.0700 & 0.4875 \\
\hline Income $f 9,999$ & -0.0304 & & 0.0656 & 0.4633 \\
\hline Income $f 12,499$ & -0.0182 & & 0.0673 & 0.2705 \\
\hline Income $f 15,599$ & -0.0702 & & 0.0714 & 0.9833 \\
\hline Income $f 20,799$ & 0.2344 & $* * *$ & 0.0726 & 3.2275 \\
\hline Income $f 25,999$ & 0.1774 & $* *$ & 0.0711 & 2.4943 \\
\hline Income $f 31,199$ & 0.2013 & $* * *$ & 0.0708 & 2.8445 \\
\hline Income $£ 31,200+$ & 0.4442 & $* * *$ & 0.0667 & 6.6625 \\
\hline Social grade $\mathrm{D}$ & 0.0599 & & 0.0432 & 1.3871 \\
\hline Social grade C2 & 0.0794 & $* *$ & 0.0396 & 2.0081 \\
\hline Social grade $\mathrm{C} 1$ & -0.0062 & & 0.0360 & 0.1716 \\
\hline Retired & -0.1259 & $*$ & 0.0659 & 1.9105 \\
\hline Unemployed & -0.1128 & * & 0.0684 & 1.6502 \\
\hline volunteer & -0.1942 & $* * *$ & 0.0427 & 4.5447 \\
\hline \multicolumn{5}{|c|}{ Indicators of satisfaction with domains of local government } \\
\hline Flood concern & 0.2051 & $* * *$ & 0.0338 & 6.0713 \\
\hline Climate concern & 0.0219 & & 0.0269 & 0.8126 \\
\hline Political efficacy & -0.0455 & * & 0.0260 & 1.7520 \\
\hline Community efficacy & 0.2466 & $* * *$ & 0.0315 & 7.8322 \\
\hline Policy experience & 0.0247 & & 0.0363 & 0.6801 \\
\hline Affective economy & -0.0346 & * & 0.0205 & 1.6893 \\
\hline Affective policy & 0.2844 & $* * *$ & 0.0188 & 15.1180 \\
\hline \multicolumn{5}{|l|}{ Ordered intercepts } \\
\hline $1 \mid 2$ & -3.0979 & $* * *$ & 0.1441 & 21.5052 \\
\hline $2 \mid 3$ & -2.4143 & $* * *$ & 0.1403 & 17.2098 \\
\hline $3 \mid 4$ & -1.7197 & $* * *$ & 0.1408 & 12.2162 \\
\hline $4 \mid 5$ & 0.0296 & & 0.1409 & 0.2097 \\
\hline Observations & 640 & & & \\
\hline
\end{tabular}

Notes:

(i) The Cragg-Uhler Pseudo- $R^{2}$ for the full sample data is 0.152 though it should be remembered that the results reported in the main table are derived from 10,000 random sub-samples. Individual Pseudo- $\mathrm{R}^{2}$ values for each sub-sample are not reported.

(ii) Reported coefficients are taken from the 10,000 random sub-samples. Specifically, to account for possible non-normalities the values are the maximum density estimates approximated using an Epanechnikov Kernel density estimate. If the sub-sample estimates are normally distributed the maximum-density estimate will be equivalent to the mean value.

(iii) Standard errors are based on the empirical distributions of the random sub-sample estimates. T-values are calculated by dividing the reported coefficient by the standard error.

(iv) Stars reflect statistical significance at the following levels: ${ }^{*}=10 \%(|t|>1.645),{ }^{* *}=5 \%(|t|>1.960),{ }^{* * *}=1 \%$ $(|t|>2.576)$. 


\section{Socioeconomic factors and satisfaction}

The coefficients on the socioeconomic variables are broadly in line with the related literature and apriori expectations. Age is found to be non-linearly related to underlying satisfaction, following a general u-shape suggesting that satisfaction is initially falling with age, then rising after a certain age. The interactive dummies of gender do not suggest any specific difference between males and females in Portsmouth, with the weak (in terms of statistical significance) implication that women are naturally less satisfied with a negative coefficient of -0.3068 . Regarding the interpretation of the u-shape effect of age, Whiteley et al. (2010) discuss this in a similar context insofar as "age reduces satisfaction, but the quadratic specification means that the effect diminishes, and then reverses very slightly, among the very elderly.", but this interpretation is a little misleading as the estimated coefficients relate to marginal probabilities. A proper interpretation of the non-linear age effect requires transforming estimated parameters to give their marginal effects.

Income effects are positive where significant, which is consistent with general economic reasoning that higher incomes households have the ability to consume more goods and services and hence achieve a higher utility/level of satisfaction in all areas of life. The social grade variables suggest that being in a higher societal position does not increase the probability of being satisfied with the political domain of local government. Noting that the reference group are intermediatemanagerial, administrative or professional workers, skilled-manual workers are the only social grade showing evidence of being happier. This suggests that in the city, social grade is possibly not synonymous with status effects in the standard manner i.e. higher social grade means a higher status, and implicitly increased happiness. The coefficient on retirement is negative.

On average, home ownership and single car ownership do not contribute, either positively or negatively, to satisfaction. This is likely due to the particular urban evolution of Portsmouth city. The naval heritage of the city has led to a high urban density, with houses being generally small terraced dwellings with limited garden frontage, and streets being narrow to maximize the residential density of the land. A consequence of this is that driving within the city is less convenient 
as parking spaces are at a premium, and where available are regulated by the local council. Multiple car ownership is seen to be associated with higher levels of satisfaction.

Education is not found to be significant. The sectoral composition of Portsmouth is such that it offers only very limited job opportunities for highly educated individuals. As such, in this location, the marginal returns to education are likely to be low even at moderate to high levels of education. Considering this point further, Table 4 highlights that the coefficient on education is not due to a lack of representation in the higher level education categories by showing the unconditional probabilities of satisfaction by education level. It can be seen that around half of the survey respondents are educated below O-level, but with a reasonable spread in the other education levels. So it can be stated that the insignificance is not due to under-representation across the education brackets. Taken together with the income/status effects, there is then a strong picture that the city is not able to generate satisfaction with the local government among the wealthy and educated parts of society. It could not be claimed from the data that this is purely connected to local government outcomes, but there is an emerging sense that the city has limited opportunities for skilled residents. 
Table 4: Unconditional probabilities of SPDLG by education level.

\begin{tabular}{cccccc|c}
\hline \hline Education level & $\begin{array}{c}\text { Very } \\
\text { dissatisfied }\end{array}$ & $\begin{array}{c}\text { Fairly } \\
\text { dissatisfied }\end{array}$ & $\begin{array}{c}\text { Neither satisfied } \\
\text { nor dissatisfied }\end{array}$ & Fairly satisfied & $\begin{array}{c}\text { Very } \\
\text { satisfied }\end{array}$ & (sum) \\
\hline Other & 0.00 & 0.02 & 0.06 & 0.30 & 0.13 & 0.51 \\
O-level & 0.00 & 0.01 & 0.03 & 0.09 & 0.05 & 0.19 \\
A-level & 0.01 & 0.01 & 0.02 & 0.10 & 0.03 & 0.17 \\
Degree & 0.00 & 0.01 & 0.02 & 0.08 & 0.03 & 0.14 \\
\hline (sum) & 0.02 & 0.05 & 0.12 & 0.57 & 0.25 & \\
\hline \hline
\end{tabular}

Notes: The education levels include equivalence level qualifications. The classifications are intended to reflect the broad key stages of education e.g. No or little formal education, pass secondary school, pass college, pass university.

As found by Clark et al. (2008) the coefficient on children is estimated to negative, hence having children does not improve satisfaction. Clark et al. (2008) offer no specific justification for this result, but possible explanations might include: children being hard to look after; less community support than in other areas; less life experience and fewer personal resources to call upon; less prospects than in other cities; an additional loci of worries in terms of schooling, child happiness etc.

\section{Indicators of satisfaction with domains of local government}

The empirical findings regarding government performance offer a different perspective than those presented by Whiteley et al. (2010). For example, Whiteley et al. (2010) find evidence that the role of affective responses to the economy are positive and significant, as opposed to the negative and significant values reported in Table 3. Similarly, they found political efficacy to be positively related to SPDLG whereas for Portsmouth city the effect proves to be negative and significant.

Considering this matter further, the policy experience variable may shed some light on the contradictory result. Whiteley et al. (2010) hypothesized that owing to the sense of empowerment that engagement with policy makers gives individuals, tangible efficacy should result in satisfaction improvements. However, the results in Table 3 further show that policy experience has no significant impact upon satisfaction with the political domain of local governance. Taken together these results may therefore imply that local residents in Portsmouth are (i) not satisfied with existing policy and hence (ii) engaging with local government to try and achieve better policy outcomes. Put another way, the result may be indicative of community engagement with local government because they 
are dissatisfied. This is conjectural since any true causal link cannot be directly established within the available data, but nonetheless offers one plausible explanation to the empirical finding.

Notwithstanding the negative coefficient, the significance of the political efficacy term is consistent with the notion that individuals value the importance of having a voice. This is further evidenced within the survey data/SPDLG model by the result on community efficacy which is also statistically significant. In contrast to political efficacy, the coefficient on community efficacy is positive. This might be inferred as indicating that Portsmouth city is underpinned by a strong sense of community.

Affective reactions to past policy and the economy are both statistically significant, but with reactions to the economy being negative while policy reactions are positive. Whiteley et al. (2010) found both to be significant. The negative coefficient on affective economy suggests that Portsmouth residents are generally unsatisfied with the economic outcomes in the city in recent years.

Figure 2 presents the calculated marginal probabilities of satisfaction type with respect to the four significant government policy indicators, namely political efficacy, community efficacy, affective economy and affective policy. This plot helps to better understand where efforts might be focused in improving satisfaction levels in Portsmouth city, since it highlights more clearly the degree to which satisfaction alters with the value of the various indicators. The implications from the figure are quite clear insofar as the most obvious improvements in satisfaction come with improved levels of affective policy; political efficacy leads to visually negligible changes in satisfaction; community efficacy reduces the share of very unsatisfied by almost the same amount as it increases the share of very satisfied; lastly for affective economy it is seen that higher values of this variable lead to a larger share of very unsatisfied individuals (reflecting the negative coefficient sign already discussed above). 
Figure 2: Marginal probabilities for key government performance indicators
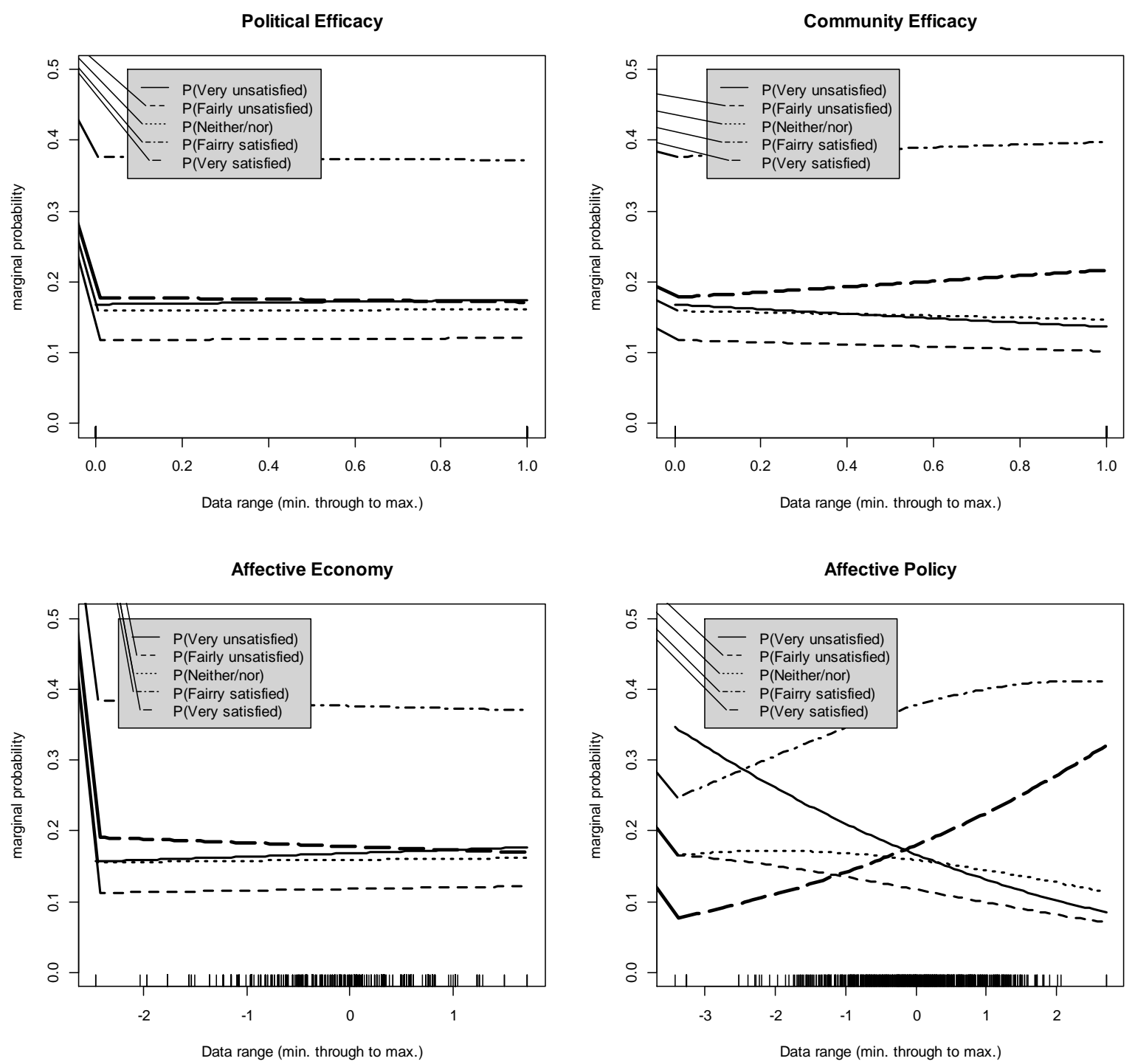

The three policy related variables: experience (insignificant), efficacy (negative and

significant) and affective (significant and positive) might seem contradictory at first; accordingly, it is worth reasserting the distinctions between these measures. Policy experience is a contemporaneous indicator of a household being a 'consumer' of a local policy at the time of the survey. It is entirely plausible that the household will not draw judgement on the true effectiveness of a policy until many months or even years after the survey, and hence consumption of the policy may not be directly related to current satisfaction with the political domain of local government. ${ }^{\text {vi }}$ Efficacy is 
actually somewhat different to the other two measures, as it defines the mediating role between local planners and consumers of policy as opposed to the outcomes of policy. Finally, affective policy describes a retrospective experiential view of policy. Differences in the estimated relationships between current experience and affective reactions might be justified on the grounds that the time lag in affective reactions allows policy outcomes to be (possibly partially) observed.

The final variables captured within the local government performance indicators are the concerns regarding flooding and climate change. As discussed, these variables indicate the household's general concerns regarding the local government ability to mitigate a local environmental threat (flooding) and a global one (climate change). Perhaps unsurprisingly, the coefficient on the global threat is insignificant. This suggests that Portsmouth's citizens do not evaluate global environmental outcomes based on local government's actions. On the other hand, concerns regarding flooding are significant and positive. This is intuitive, as the problem is highly localized, especially given the island nature of the city, hence the likelihood of flooding in the city is a direct consequence of local mitigation activities, subject to capital/resource availability. In contrast climate change is effectively exogenously determined. While the residents of Portsmouth can play their role in adaptation towards climate change, the nature of climate change is determined on a global scale and hence a sense of ownership of the problem is greatly reduced.

\section{Policy discussion: What can local governments do with such information?}

Two outstanding questions deserve further consideration: firstly given the results, how might the local authorities in Portsmouth proceed with an objective of improving satisfaction among their residents?; secondly to what extent are the lessons learned from Portsmouth city likely to be transferable to other contexts.

The general message presented by the results is that having a 'voice' (as reflected through the efficacy variables, both political and community) is not synonymous with improvements in satisfaction with the performance of the local government. This gives rise to a first policy objective, 
namely to improve the depth and quality of dialogue between residents and the council. The survey work did not provide in depth information to allow for the symptoms of this result to have emerged but some plausible options can be suggested; (i) there are not enough routes (or forms/mechanisms) for dialogue; (ii) the dialogue is one-sided with insufficient feedback; (iii) any feedback provided is either not timely or not detailed enough. Though far from comprehensive, (i)(iii) are broad enough to encapsulate the core components of communication that may lead to disaffection and a feeling of bluntness within the communication protocols. Pragmatic steps might therefore be to conduct a resident survey concentrating on 'communication and community feedback' to elaborate a richer picture on how communication can become a reinforcer of positive emotive outcomes e.g. to improve happiness/satisfaction with local government.

The second route of action implied by the empirical results is to maximise exposure to policy (implied by the results on affective policy). Taken together the results point towards the fact that 'policy experience today leads to happiness tomorrow'. With improving satisfaction as the primary objective this highlights that ensuring already available policy instruments are successfully delivered to all those who are eligible, could be a sensible course of action. It might be felt that in a period of fiscal constraint that pursuing this route might result in a less desirable higher cost for local government, though this may be misleading since policies are normally advocated after a lengthy (full-economic) cost-benefit assessment which helps ensure they deliver at least as many benefits, albeit indirect in some cases, as costs incurred. This second route may in fact also overlap to some degree with the process of communication, as it is inevitably true that policies are only revealed when directly searching for them, but when not knowing what to search for, they are seldom revealed. More precisely increased communication from the local government as to the menu of policy instruments that households are eligible for, could increase their uptake (implicitly improving overall societal welfare) and raise levels of satisfaction with the local government at the same time.

\section{Conclusions}


In this city, affective reactions to the economy are negative. There is a possibility that these issues are subject to complex inter-connectedness in a way that the data simply does not have the scope to reveal. However, some intuition can be postulated. A lack of local highly skilled job opportunities and avenues by which to overtly express status (and hence gain extrinsic rewards for contributions to society) reduces the value of having them in this city. Not wishing to move back down the income/social ladders, such individuals may instead look to relocate to another city or may have done so already.

Hence, those individuals that can generate positive economic contributions are likely to leak from the city, and accordingly the local economy weakens. This could in turn contribute to the generation of the wider sample's sense of negativity towards the affective economy, which is an experiential measure requiring time in which to establish stable preferences.

Seemingly being a well-educated, high income and high societal status individual does not currently have a positive pay-off in the City of Portsmouth with respect to being satisfied with the political domain of local government. Income, education and social status are all negatively related to happiness. It is likely that the result would vary considerably across other city jurisdictions in the UK and elsewhere. 


\section{References}

Anderson, Christopher J. and Guillory, Christine, A. (1997) Political institutions and satisfaction with democracy: A Cross-National analysis of consensus and majoritarian systems, American Behavioral Scientist 91(1) 66-81.

Clark, Andrew. E., Ed Diener, Yannis Georgellis and Richard E. Lucas. 2008. “Lags and leads in life satisfaction: A test of the baseline hypothesis" Economic Journal, 118 (529): F222-F243.

Dolan, Paul, Tessa Peasgood and Mathew White. 2008. "Do we really know what makes us happy? A review of the economic literature on the factors associated with subjective well-being" Journal of Economic Psychology 29 (1): 94-122.

Ferrer-i-Carbonell, Ada and Paul Frijters. 2004. "How important is methodology for the estimates of the determinants of happiness?" Economic Journal 114 (497): 641-659.

Luechinger, Simon and Paul A. Raschky. 2009. "Valuing flood disasters using the life satisfaction approach", Journal of Public Economics, 93 (3-4): 620-633.

Okulicz-Kozaryn, Adam. 2013. "City life: Rankings (livability) versus perceptions (satisfaction)" Social indicators research, 110 (2): 433-451.

Okulicz-Kozaryn, Adam. 2014. Changes across the region: people, economy and wellbeing. Rutgers University (Senator Walter Rand Institute for Public Affairs) discussion paper available online at: http://wrand.rutgers.edu/files/Adam-Okulicz-Kozaryn-Changes-Across-the-Region.pdf. Portsmouth City Council (2012) http://www.portsmouth.gov.uk/ [date accessed: 04/11/2012]] Torcal, Mariano and Montero, José Ramón (2006) Political Disaffection in Contemporary Democracies: Social Capital, Institutions and Politics, London, Routledge Books. 
Whiteley, Paul, Harold D. Clarke, David Sanders and Marianne C. Steward. M.C., 2010, “Government Performance and Life Satisfaction in Contemporary Britain", The Journal of Politics, 72(3): 733-746. 


\section{Appendix 1: Summary of principal component analysis for 'affective policy' and 'affective}

economy'.

The variables 'affective policy' and 'affective economy' are each constructed as the leading indicator from two separate principal component analyses. Each of these analyzes uses a different set of questions relating respondent's views regarding the two aspects, i.e. policy issues, and issues relating to economic performance. Specifically, for each of the categories below, the respondent was asked "The following are Portsmouth City Council's current priorities for improvement in the city. How successful or unsuccessful would you say the council is being in dealing with them?", being asked to respond on a 5-point Likert scale ranging from 1 for very successful, to 5 for very unsuccessful.

In constructing the 'affective policy' factor questions regarding the success of the local council with respect to:

- Reducing the fear of crime;

- Making Portsmouth a citer where people are safer;

- Reducing anti-social behaviour;

- Reducing violent crime;

- Improving educational attainment;

- Promoting Portsmouth as a city with a distinctive culture;

- Keeping the city clean;

- Maintaining and developing the quality and design of buildings and public spaces in the city;

- The provision of public transport;

- Improving facilities for walking and cycling;

- Tackling traffic congestion;

- Promoting and enhancing road safety;

- Providing and maintaining parking provision; and

- Protecting and supporting vulnerable adults and children. 
Hence the resulting factor characterizes experiential viewpoints of residents in relation to a range of policy areas, particularly crime, education and transport.

Constructing the 'affective economy' factor uses questions regarding the success of the local council with respect to:

- Having a thriving economy;

- Enhancing the living standards in the city's most deprived areas; and

- Being more efficient and effective in everything the council does.

\section{Appendix 2: A fourfold typology of households that are satisfied/unsatisfied and those that are critical/uncritical of the effectiveness of local policy}

Descriptive statistics are offered based on a simple fourfold typology looking into the characteristics of households that are: satisfied and with an uncritical perspective of local policy (measured in terms of having an 'affective policy' score in the upper $15 \%$ of households); satisfied and with a critical perspective of local policy (measured in terms of having an 'affective policy' score in the lower 15\% of households); unsatisfied and with an uncritical perspective of local policy (measured in terms of having an 'affective policy' score in the upper $15 \%$ of households) and; unsatisfied and with a critical perspective of local policy (measured in terms of having an 'affective policy' score in the lower $15 \%$ of households). The values in the table are discussed in the main text

Table Appendix B-1: Mean values of key variables by happiness type.

\begin{tabular}{lcccc}
\hline \hline \multicolumn{1}{c}{ SPDLG level: } & \multicolumn{2}{c}{ Satisfied } & \multicolumn{2}{c}{ Unsatisfied } \\
Socioeconomic indicators & Uncritical & Critical & Uncritical & Critical \\
Age & 43.6889 & 48.1594 & 50.1667 & 52.5769 \\
Female & 0.5000 & 0.5217 & 0.5000 & 0.5000 \\
Disabled (self) & 0.0889 & 0.1884 & 0.0000 & 0.2308 \\
Disabled (other) & 0.8667 & 0.9130 & 1.0000 & 0.6923 \\
Non-white & 0.1333 & 0.0580 & 0.1667 & 0.0769 \\
Home ownership & 0.3222 & 0.3043 & 0.5000 & 0.3846 \\
Vehicle ownership (single) & 0.4889 & 0.3768 & 0.6667 & 0.4615 \\
Vehicle ownership (multiple) & 0.1556 & 0.2319 & 0.1667 & 0.1923
\end{tabular}




\begin{tabular}{|c|c|c|c|c|}
\hline Children & 0.3111 & 0.2319 & 0.1667 & 0.2692 \\
\hline Education & 1.9000 & 2.2754 & 1.1667 & 2.2692 \\
\hline Income $£ 4,999$ & 0.0444 & 0.0290 & 0.0000 & 0.0769 \\
\hline Income $f 7,499$ & 0.0778 & 0.1739 & 0.0000 & 0.1923 \\
\hline Income $f 9,999$ & 0.0889 & 0.1594 & 0.0000 & 0.1154 \\
\hline Income $f 12,499$ & 0.1222 & 0.1014 & 0.1667 & 0.1154 \\
\hline Income $£ 15,599$ & 0.1444 & 0.0725 & 0.1667 & 0.1538 \\
\hline Income $f 20,799$ & 0.0778 & 0.0435 & 0.1667 & 0.0000 \\
\hline Income $£ 25,999$ & 0.0889 & 0.0580 & 0.0000 & 0.0000 \\
\hline Income $£ 31,199$ & 0.1444 & 0.0290 & 0.1667 & 0.1538 \\
\hline Income $£ 31,200+$ & 0.1444 & 0.2754 & 0.3333 & 0.1538 \\
\hline Social grade $\mathrm{D}$ & 0.1333 & 0.2319 & 0.0000 & 0.2308 \\
\hline Social grade $\mathrm{C} 2$ & 0.2000 & 0.2029 & 0.1667 & 0.1154 \\
\hline Social grade $\mathrm{C} 1$ & 0.3889 & 0.2464 & 0.6667 & 0.1923 \\
\hline Retired & 0.2556 & 0.2899 & 0.1667 & 0.3462 \\
\hline Unemployed & 0.0333 & 0.0580 & 0.0000 & 0.0000 \\
\hline volunteer & 0.0889 & 0.0725 & 0.0000 & 0.0769 \\
\hline \multicolumn{5}{|c|}{ Indicators of satisfaction with domains of local government } \\
\hline Flood concern & 0.3333 & 0.1304 & 0.3333 & 0.1154 \\
\hline Climate concern & 0.3667 & 0.2319 & 0.5000 & 0.1538 \\
\hline Political efficacy & 0.3778 & 0.5217 & 0.1667 & 0.2308 \\
\hline Community efficacy & 0.4000 & 0.1304 & 0.8333 & 0.0769 \\
\hline Policy experience & 0.1889 & 0.2174 & 0.1667 & 0.0769 \\
\hline Affective economy & 0.6747 & -0.8560 & 0.4542 & -0.7482 \\
\hline Affective policy & 1.3136 & -1.5143 & 1.1520 & -1.6220 \\
\hline Observations & 90 & 69 & 6 & 26 \\
\hline
\end{tabular}

\section{Endnotes}

\footnotetext{
i For further detail about the distinctive characteristics of this island city, the interested reader may also refer to the Portsmouth City Council website at: https://www.portsmouth.gov.uk.

ii This was however attempted with early specifications using the same grid search approach described by Luechinger and Raschky (2009). The 'optimal' risk parameter was estimated to be about -19 . This value is extremely large, though not entirely implausible, however as described, this approach was not pursued owing to the inconsistent income bracket band sizes.
}

iii In this paper the variable names 'affective policy' and 'affective economy' are used for consistency with previous related literature, though it is worth noting these variables might also be described more completely as cognitive evaluations of government performance with respect to various specific functions.

iv In separate research using the same data, missing-data analysis including imputation of missing values has been conducted to maximise the available number of observations. The Monte-Carlo estimation procedure is nonetheless favoured as it reveals more information on the robustness of identified relationships by giving the approximate complete empirical coefficient distribution.

${ }^{v}$ This approach bears some resemblance to Bootstrap estimation methods, however in the present situation is preferred to Bootstrap approaches as it helps to mitigate potential missing data bias. 
vi This might imply something about the expectations of policy outcomes insofar as a consistently positive (negative) expectation might increase (decrease) current period satisfaction under the expectation of better (worse) future life quality. 